\title{
Evaluation of Vehicle Performance Based on Set Pair Analysis
}

\author{
Jian Zhang, Mingjun Li, Liping Wang \\ School of Transportation and Automobile Engineering, Panzhihua University, China \\ *zhangjianpzh@126.com
}

\begin{abstract}
Keywords: vehicle performance; set pair; four-element connection number; comprehensive evaluation
\end{abstract}

\begin{abstract}
An evaluation method of vehicle performance based on set pair analysis was proposed. The evaluating index system of vehicle performance was constructed by setting five first-level evaluation indexes and thirteen second-level evaluation indexes. The evaluation models were constructed by using four-element connection number of set pair theory for quantitative evaluation and qualitative evaluation of vehicle performance. The linear relationship and the comparative analysis between the evaluation results and consumer ratings by evaluating the performance of 6 similar vehicles showed that this evaluation method was scientific, effective and had good practicability.
\end{abstract}

\section{Introduction}

After more than one hundred years of development, the automobile has become an indispensable means of transport in human life. Automobiles have also become the pillar industries in social and economic development. In the increasingly sophisticated automobile consumption, the performance of automobile has caused widespread concern. Vehicle performance (overall performance) are related to a number of factors such as economy, power, handling stability, environmental protection, safety, comfort and others. Due to the differences between the correlation of the various factors on the performance of automobile are difficult to determine, apparently according to the evaluation of individual indicators may result in poor evaluation of the compatibility issues [1]. Therefore, it is necessary to establish a scientific, reasonable and simple method for evaluating the performance of the entire vehicle. The evaluation of the target vehicle performance by using the comprehensive performance evaluation model based on set theory can overcome the problems of many factors and different degrees of influence affecting the vehicle performance.

\section{Vehicle Performance Evaluation Index System}

There are many factors that affect the overall performance of a vehicle, including the use of performance and non-use performance. Automotive performance is mainly related to automotive power, economy, comfort, accessibility, security and so on. Automotive non-use features include the appearance and interior of the car. For the evaluation of non-use performance, in addition to the vehicle itself, the level of technology, and personal preferences are still a great relationship. In order to exclude the impact of personal preferences, the established vehicle performance evaluation index system is based on the performance of the vehicle [2].

Scientific and reasonable vehicle overall performance evaluation index system should have the following requirements: (1) Comparability. Regardless of vehicle size, not only vertical comparison but also horizontal comparison can be performed and easy to put forward unified evaluation criteria; 
(2) Maneuverability. Determination of all indicators of the parameters should be achieved in the car without disintegration, and the parameters do not need conversion, user-friendly; (3) Simple and clear. Scientific and reasonable vehicle evaluation index number should be as clear as possible, and can comprehensively reflect the performance of the car [3]. Based on the above criteria, the automobile comprehensive performance evaluation index system was established. As shown in Figure 1.

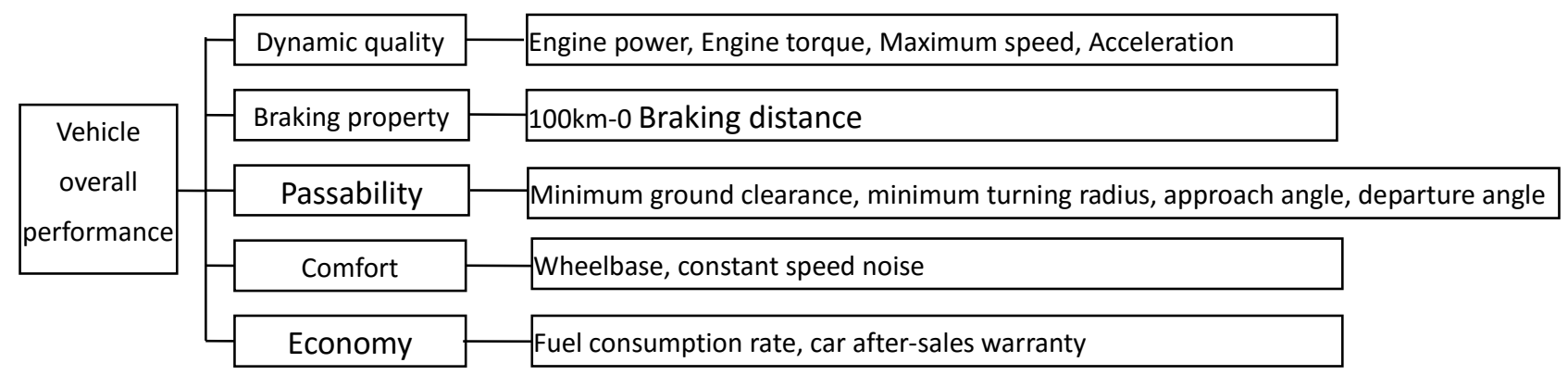

Figure 1. The evaluating index system of vehicle

\section{Vehicle Performance Evaluation Model Based on Set Pair Theory}

\subsection{Set Pair Theory and Four-element Connection Number}

Set pair analysis is a method which can study a variety of uncertain issues. The core idea is to think the object of study as determining systems and uncertain systems [4][5]. Set pair is a pair consisting of two sets with certain relationship. Set pair analysis study uncertainty problems from the identical, discrepant and contrary three aspects and create the identical-discrepant-contrary (IDC) contact degree of the set pair. Then we can get the mathematical expression of contact degree of the issues which the two sets study. Four-element connection number is extending about the identical, discrepant and contrary of set pair analysis, in which the discrepant will be subdivided into discrepant with identical-migraine and discrepant with contrary-migraine. The expression of four-element connection number can be expressed as

$$
\begin{aligned}
& \mu=a+b i+c j+d k \\
& a \in[0,1], b \in[0,1], c \in[0,1], d \in[0,1], a+b+c+d=1
\end{aligned}
$$

In the formula (1), $i$ - the degree of difference of discrepant with identical-migraine; $j$ - the degree of difference of discrepant with contrary-migraine; $k$ - the degree of contrary.

Four-element connection number can be various operations from different angles or according to the solving requirements of different problems. The actual value of the index indicators and standard value of the index indicators of the vehicle performance evaluation are as two sets when we use set pair theory to evaluate the vehicle performance, and the two sets are as a set pair $\{\mathrm{X}, \mathrm{Y}\}$.

\subsection{Automobile Performance Index Grade Division}

Each evaluation index value of the car performance from superior to poor is divided into four levels, so you can easily use set theory to evaluate the overall performance of the vehicle. For example, we are evaluating the comprehensive performance of the six target vehicles, first collecting the parameter configuration of each target vehicle. Taking engine power as an example, the engine power of the six cars is respectively $90 \mathrm{KW}, 112 \mathrm{KW}, 97 \mathrm{KW}, 120 \mathrm{KW}, 136 \mathrm{KW}$ and $118 \mathrm{KW}$. From these six engine power parameters $136 \mathrm{KW}$ can be seen as the maximum, saying the value is the optimal value. $90 \mathrm{KW}$ is the minimum value, saying the value is the worst value. Thus, an engine power parameter interval $[90,136]$ is obtained. If we evaluate the target cars by using four-element connection number theory, we divide the interval into four parts. The poor interval 
[90,101.5], the medium interval [101.5,112], the good interval $[112,123.5]$ and the excellent interval $[123.5,136]$ can directly rank the engine power of each car. Engine power of $90 \mathrm{KW}$ corresponds to the poor range, the index level is poor, marked as A-. The engine power of several other vehicles corresponds to the excellent range, the good range, the medium range and the poor range, respectively, abbreviated as $\mathrm{A}++, \mathrm{A}+, \mathrm{A}, \mathrm{A}-$. Similarly, for the other two indicators of vehicle performance can be graded according to this method. Particular emphasis is given to the fuel consumption rate of the second-level indicator. The vehicle with the smallest parameter value corresponds to the highest grade of the indicator, which is contrary to the principle of the other second-level indicator grades.

\subsection{Vehicle Performance Evaluation Model}

Vehicle First-level Index Evaluation Model. According to the level of the second-level index corresponding to the first-level index, the evaluation model of the fourth-level connection number is established. In vehicle performance evaluation, define secondary level indicators feature weights $\omega_{l m}(m=1,2, \cdots, n)$, then the evaluation of four-element connection number for the $l$ th first-level indicator can be expressed as

$$
\mu=\sum_{m=1}^{S} \omega_{l m}+\sum_{m=1+S}^{F} \omega_{l m} i+\sum_{m=1+S+F}^{H} \omega_{l m} j+\sum_{m=1+S+F+H}^{P} \omega_{l m} k=a_{1}+b_{1} i+c_{l} j+d_{l} k
$$

In the formula (2), $S$-The secondary indicators number of A++ grade under the $l$ th first-level indicator, $F$-The secondary indicators number of A+grade, $H$-The secondary indicators number of A grade, $P$ - The secondary indicators number of A- grade.

Comprehensive Evaluation Model of Vehicle Performance. According to the evaluation rules from low level to high level, after getting the four-element connection number of each first-level index evaluation, the comprehensive performance evaluation model of the automobile can be established. Defining the weight of the first-level index features $\omega_{l}\left(l=1,2, \cdots, z, \sum_{l=1}^{z} \omega_{l}=1\right)$, we can get the comprehensive performance evaluation model of the vehicle, as shown in equation (3).

$$
u=\left(\omega_{1}, \omega_{2}, \ldots \omega_{Z}\right)\left[\begin{array}{cccc}
a_{1} & b_{1} & c_{1} & d_{1} \\
a_{2} & b_{2} & c_{2} & d_{2} \\
\ldots & \ldots & \ldots & \ldots \\
a_{1} & b_{1} & c_{1} & d_{1}
\end{array}\right]\left[\begin{array}{l}
1 \\
i \\
j \\
k
\end{array}\right]
$$

\section{Example Calculation}

There are 6 cars to be evaluated as q1, q2, q3, q4, q5 and q6 respectively. Applying the vehicle performance evaluation model based on set theory, the vehicle performance of the six cars are evaluated comprehensively and the evaluation results are obtained.

\subsection{Determine the Weight of Evaluation Index}

Establish a Multi-level Analysis of the Structural Model. Including the target layer, the guideline layer, the index layer, in which the vehicle overall performance $A$ is the target layer, dynamic quality $\mathrm{B}_{1}$, brake property $\mathrm{B}_{2}$, passability $\mathrm{B}_{3}$, comfort $\mathrm{B}_{4}$, economy $\mathrm{B}_{5}$ as the standard layer. The car performance evaluation indicators named $\mathrm{C}_{1}-\mathrm{C}_{13}$ including engine power, engine torque, maximum speed, acceleration, braking distance, minimum ground clearance, minimum turning radius, approach angle, departure angle, wheelbase, constant speed noise, fuel consumption and car after-sales warranty as a layer. 
Calculate Weights and Consistency Checks. Using AHP to calculate weights [6]. We can get the calculation result $\omega_{l}=\{0.18,0.25,0.121,0.056,0.393\}$ by computing target layer - criterion layer, constructing A-B judgment matrix and consistency test, and normalizing weights. In the same way according to the above method to calculate the standard layer - index layer, construct B-C judgment matrix, the calculation results shown in Table I.

Table I The weights calculation results

\begin{tabular}{cccccccccc}
\hline $\mathrm{B}_{1}$ & $\omega$ & $\mathrm{B}_{2}$ & $\omega$ & $\mathrm{B}_{3}$ & $\omega$ & $\mathrm{B}_{4}$ & $\omega$ & $\mathrm{B}_{5}$ & $\omega$ \\
\hline $\mathrm{C}_{1}$ & 0.282 & $\mathrm{C}_{5}$ & 1 & $\mathrm{C}_{6}$ & 0.311 & $\mathrm{C}_{10}$ & 0.529 & $\mathrm{C}_{12}$ & 0.607 \\
$\mathrm{C}_{2}$ & 0.266 & & & $\mathrm{C}_{7}$ & 0.211 & $\mathrm{C}_{11}$ & 0.471 & $\mathrm{C}_{13}$ & 0.393 \\
$\mathrm{C}_{3}$ & 0.189 & & & $\mathrm{C}_{8}$ & 0.239 & & & & \\
$\mathrm{C}_{4}$ & 0.263 & & & $\mathrm{C}_{9}$ & 0.239 & & & & \\
\hline
\end{tabular}

\subsection{Collect Performance Parameters of the Cars to be Evaluated and Classify the Indexes}

Based on the established vehicle performance evaluation index system, the parameter table is obtained according to the collected vehicle technical condition parameters, as shown in Table II.

Table II Collected automotive technical performance data

\begin{tabular}{ccccccc}
\hline Performance & $\mathrm{q} 1$ & $\mathrm{q} 2$ & $\mathrm{q} 3$ & $\mathrm{q} 4$ & $\mathrm{q} 5$ & $\mathrm{q} 6$ \\
\hline Engine power $/ \mathrm{kw}$ & 120 & 165 & 135 & 130 & 125 & 242 \\
Engine torque $/ \mathrm{N} \bullet \mathrm{m}$ & 246 & 350 & 270 & 259 & 280 & 475 \\
Maximum speed //m/h & 192 & 230 & 202 & 190 & 197 & 209 \\
Acceleration / s & 15.06 & 7.080 & 8.080 & 13.77 & 7.900 & 7.500 \\
100km-0 Braking distance /m & 43.79 & 39.92 & 38.52 & 43.54 & 39.4 & 39.92 \\
Minimum ground clearance /mm & 220 & 170 & 185 & 235 & 180 & 201 \\
Minimum turning radius /m & 5.8 & 5.9 & 5.9 & 5.7 & 6.2 & 5.75 \\
Approach angle / degree & 28 & 18 & 18 & 36.6 & 18 & 22 \\
Departure angle / degree & 25 & 23 & 22 & 25 & 28 & 23 \\
Wheelbase /cm & 2790 & 2807 & 2760 & 2780 & 2604 & 2670 \\
60km/h Noise /dB & 62.3 & 60.3 & 60.5 & 61.7 & 60.1 & 61.4 \\
Fuel consumption rate /L & 13 & 11.3 & 7.6 & 12.4 & 9.4 & 8.5 \\
Car after-sales warranty /year & 3 & 3 & 3 & 5 & 3 & 3 \\
\hline Accorcing to the establishment
\end{tabular}

According to the establishment of the index classification rules to evaluate each grade of two indicators. The results are shown in Table III.

Table III Vehicle comprehensive performance index grade division

\begin{tabular}{ccccccc}
\hline \multirow{2}{*}{ Performance } & \multicolumn{7}{c}{ Indicator grade } \\
\cline { 2 - 7 } & $\mathrm{q} 1$ & $\mathrm{q} 2$ & $\mathrm{q} 3$ & $\mathrm{q} 4$ & $\mathrm{q} 5$ & $\mathrm{q} 6$ \\
\hline Engine power $/ \mathrm{kw}$ & $\mathrm{A}-$ & $\mathrm{A}$ & $\mathrm{A}-$ & $\mathrm{A}-$ & $\mathrm{A}-$ & $\mathrm{A}++$ \\
Engine torque $/ \mathrm{N} \bullet \mathrm{m}$ & $\mathrm{A}-$ & $\mathrm{A}+$ & $\mathrm{A}-$ & $\mathrm{A}-$ & $\mathrm{A}-$ & $\mathrm{A}++$ \\
Maximum speed $/ \mathrm{km} / \mathrm{h}$ & $\mathrm{A}-$ & $\mathrm{A}++$ & $\mathrm{A}$ & $\mathrm{A}-$ & $\mathrm{A}-$ & $\mathrm{A}$ \\
Acceleration $/ \mathrm{s}$ & $\mathrm{A}++$ & $\mathrm{A}-$ & $\mathrm{A}-$ & $\mathrm{A}++$ & $\mathrm{A}-$ & $\mathrm{A}-$ \\
$100 \mathrm{~km}-0$ Braking distance $/ \mathrm{m}$ & $\mathrm{A}++$ & $\mathrm{A}$ & $\mathrm{A}-$ & $\mathrm{A}++$ & $\mathrm{A}$ & $\mathrm{A}$ \\
Minimum ground clearance $/ \mathrm{mm}$ & $\mathrm{A}++$ & $\mathrm{A}-$ & $\mathrm{A}-$ & $\mathrm{A}++$ & $\mathrm{A}-$ & $\mathrm{A}$ \\
Minimum turning radius $/ \mathrm{m}$ & $\mathrm{A}-$ & $\mathrm{A}+$ & $\mathrm{A}+$ & $\mathrm{A}-$ & $\mathrm{A}++$ & $\mathrm{A}-$ \\
Approach angle $/$ degree & $\mathrm{A}+$ & $\mathrm{A}-$ & $\mathrm{A}-$ & $\mathrm{A}++$ & $\mathrm{A}-$ & $\mathrm{A}$ \\
Departure angle / degree & $\mathrm{A}++$ & $\mathrm{A}++$ & $\mathrm{A}++$ & $\mathrm{A}++$ & $\mathrm{A}-$ & $\mathrm{A}$ \\
Wheelbase $/ \mathrm{cm}$ & $\mathrm{A}++$ & $\mathrm{A}++$ & $\mathrm{A}++$ & $\mathrm{A}++$ & $\mathrm{A}-$ & $\mathrm{A}$ \\
60km/h Noise $/ \mathrm{dB}$ & $\mathrm{A}++$ & $\mathrm{A}-$ & $\mathrm{A}-$ & $\mathrm{A}-$ & $\mathrm{A}+$ & $\mathrm{A}+$ \\
Fuel consumption rate $/ \mathrm{L}$ & $\mathrm{A}-$ & $\mathrm{A}-$ & $\mathrm{A}++$ & $\mathrm{A}-$ & $\mathrm{A}$ & $\mathrm{A}++$ \\
Car after-sales warranty $/ \mathrm{year}$ & $\mathrm{A}-$ & $\mathrm{A}-$ & $\mathrm{A}-$ & $\mathrm{A}++$ & $\mathrm{A}-$ & $\mathrm{A}-$ \\
\hline
\end{tabular}

\subsection{Evaluate the Target Vehicle Performance Using the Evaluation Model}

Applying the established evaluation model to evaluate the overall performance of the vehicle q1, 
we can obtain the four-element connection number of the comprehensive performance evaluation.

$$
\begin{aligned}
& u_{q 1}=\left[\begin{array}{lllll}
0.180 & 0.250 & 0.121 & 0.056 & 0.393
\end{array}\right]\left[\begin{array}{ccccc}
0.263 & 0 & 0 & 0.737 \\
1.0 & 0 & 0 & 0 \\
0.55 & 0.239 & 0 & 0.211 \\
1.0 & 0 & 0 & 0 \\
0 & 0 & 0 & 1.0
\end{array}\right]\left[\begin{array}{l}
1 \\
i \\
j \\
k
\end{array}\right] \\
& =0.420+0.029 \mathrm{i}+0.551 \mathrm{k}
\end{aligned}
$$

Similarly, we can get the target vehicle q2, q3, q4, q5, q6 the four-element connection number of the comprehensive performance evaluation.

$$
\begin{aligned}
& u_{q 2}=0.093+0.073 i+0.301 j+0.533 k \\
& u_{q 3}=0.297+0.026 i+0.034 j+0.643 k \\
& u_{q 4}=0.577+0.423 k \\
& u_{q 5}=0.026+0.026 i+0.489 j+0.46 k \\
& u_{q 6}=0.337+0.026 i+0.409 j+0.227 k
\end{aligned}
$$

\subsection{The Evaluation Results Discussion}

Vehicle comprehensive performance score can reflect the automotive consumer groups on vehicle performance recognition. Respectively assigned variables $i, j, k$ value of $0.75,0.5,0.25$, calculate the result of the contact number.

At the same time, in order to facilitate the analysis of evaluation results, the variable $\mathrm{P}$ is defined as a reference, as shown in formula (10), in which the consumer ratings and the contact numbers are similar in dimension.

$P=$ (each contact number-each contact number)/ each contact number

The calculation of the number of contacts, consumer ratings and $\mathrm{P}$ values are shown in Table IV. Table IV Evaluation results comparison

\begin{tabular}{ccccccc}
\hline Target vehicle & $\mathrm{q} 1$ & $\mathrm{q} 2$ & $\mathrm{q} 3$ & $\mathrm{q} 4$ & $\mathrm{q} 5$ & $\mathrm{q} 6$ \\
\hline Contact numbers & 0.580 & 0.432 & 0.494 & 0.683 & 0.405 & 0.618 \\
Consumer ratings & 4.47 & 4.31 & 4.32 & 4.45 & 4.17 & 4.43 \\
$P$ value & 0.843 & 0.883 & 0.899 & 0.849 & 0.894 & 0.869 \\
\hline
\end{tabular}

Establish an evaluation result and a Chinese domestic car site consumer rating comparison chart to analyze the evaluation results, as shown in Figure 2. The P value curve has small fluctuation, and the $\mathrm{P}$ value of each target vehicle is approximately linear, indicating that the evaluation result is more scientific, effective and of reference value. The identical characteristic degree curve fluctuates the most, which shows that it is not advisable to conclude the comprehensive performance of the vehicle by considering only the same degree, and needs to consider both the effect of the degree of divergence and the degree of oppositeness on the performance of the vehicle. Through the curve of the contact number, we can get an objective ranking of these six car performance ranks, that is, q4> q6> q1> q3> q2> q5.

The consumer score curve shows people's recognition of the overall performance of the vehicle in actual situations, observing the contact degree curve and the consumer rating curve. The trend of these two curves is roughly the same, and the evaluation result is consistent with most of the ratings. However, we can see that the conclusion of the connection number is slightly different from that of the consumer score, and the third highest ranked q1 consumer score. The reason is that the evaluation model is established based on the performance (the evaluation conclusion is more objective), and the current brand factors and personal preferences will also have a major impact on 
the domestic automobile consumers in China. For example, German joint venture models in the Chinese auto market after a long time reputation, high visibility, q1 score for such reasons.

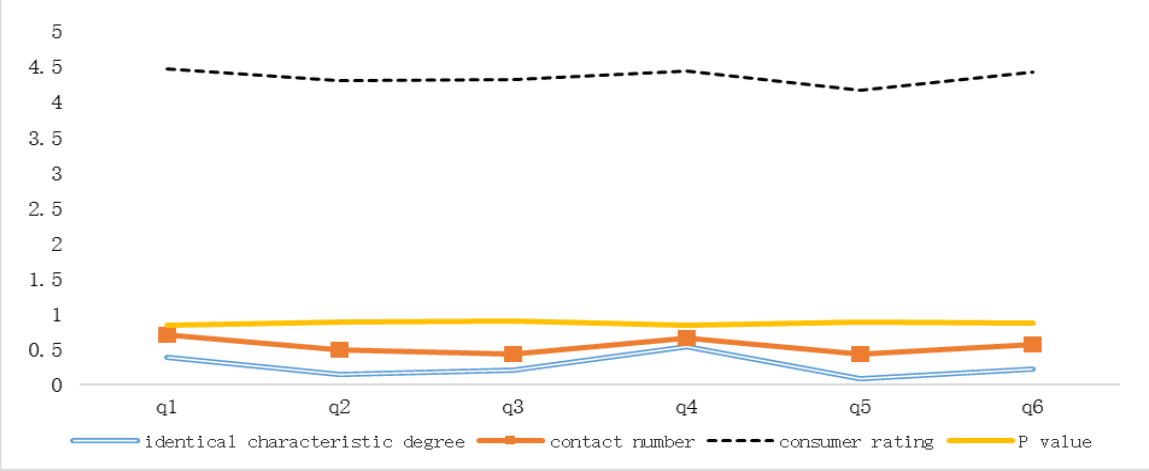

Figure 2. Evaluation results and consumer ratings comparison

\section{Conclusions}

According to the comprehensive evaluation of vehicle performance, the vehicle performance evaluation model based on set theory sets not only the identity of the problem but also the opposition and difference of the problem. The practical application showed that the set pair evaluation model could synthesize the index information, and was more scientific than the single index information evaluation, so as to more fully reflect the vehicle performance. Therefore, this method provides an effective new approach for the comprehensive evaluation of vehicle performance and is simple, easy to implement and has good practical value.

\section{Acknowledgment}

In this paper, the research was sponsored by 2014 Research Program of Education Office of Sichuan Province (Project No. 14ZB0409).

\section{References}

[1] Song GAO, Jide ZHUANG, Chuanbo REN, etc. Vehicles performance optimization[M]. Beijing: Machinery Industry Press, 2008.

[2] Ling-yan CHANG, Kun ZHAO, Chong-liang JIN, etc. Study on intelligent synthetic evaluation of vehicle collective performance[J]. Machinery Design \& Manufacture, 2010(3): 246-248.

[3] Huaji WANG, Changfu ZONG, Xin GUAN, etc. Method of Determining Weights of Subjective Evaluation Indexes for Car Handling and Stability Based on Fuzzy Analytic Hierarchy Process[J]. CHINESE JOURNAL OF MECHANICAL ENGINEERING， 2011， 47 (24):83-90.

[4] Meng YANG. Evaluation Model of Vector Map Watermarking Algorithms Base on Set Pair Analysis[J]. COMPUTER SCIENCE,2017, 44(S2): 357-361.

[5] Zhongming HE, Ke LIU, Hongyuan FU, etc. Safety risk assessment of high slope blasting construction based on set pair-extension analysis[J]. Journal of Central South University (Science and Technology),2017,48(08):2217-2223.

[6] Jian ZHANG, Xiaoying LIU, Liping WANG. Risk Evaluation for Selection of Mine Trucks Based on Analytic Hierarchy Process[J]. Journal of Shenyang University(Natural Science).2014, $26(5): 426-430$. 